\title{
Valor y crematística: el testimonio del castellano medieval
}

\author{
Carmen Benito Vessels
}

Este trabajo parte de un recorrido por el concepto de valor y las formas que ha asumido a lo largo del tiempo en disciplinas como la economía, la literatura, la filosofía, y la filología. Se señalan los hitos históricos y filosóficos más importantes de la cultura crematística en relación con la lengua, prestando especial atención a las expresiones crematísticas producidas en castellano durante el medievo español, durante el cual la ponderación de la palabra como bien común y como fuente de riqueza fue un tema compartido por judíos, cristianos y musulmanes. En la última parte se hace una relación de las expresiones crematísticas que vinculan lo económico con lo lingüístico en dos textos medievales: Bocados de oro y el Poema de Mio Cid. El primero, un tratado sapiencial divulgado en lenguas semíticas y traducido del árabe al castellano en el siglo XIII, tiene como tema central el valor contenido en la lengua. En el segundo las expresiones crematísticas se multiplican, pero no siempre hacen referencia a asuntos monetarios sino que se extienden al campo de la lengua y de la cultura en general.

Palabras clave: Castellano medieval, crematística, Bocados de Oro, Poema de Mio Cid, valor.

This essay starts with an overview of the concept of value, and the ways in which it has been shaped through the years by disciplines such as economy, literature, philosophy and philology. Key historical and philosophical moments of crematistic culture in relation to language are pointed out, paying special attention to crematistic expressions produced in Medieval Spanish, a time when words were valued as common goods as well as sources of richness by the three main cultures flourishing in Spain: Christians, Muslims and Jews. The last part offers a list of crematistic expressions in which economic and lingüistic values are linked together, taken from two medie- 
val works: Bocados de oro and Poema de Mio Cid. The former, a didactic treatise translated from the Arabic in the 13th century, has as its main topic the value within language. In the latter, crematistic expressions proliferate, but not always refer to monetary issues; rather, their meaning reaches for the realms of language and culture.

Keywords: Medieval Spanish, crematistics, Bocados de Oro, Poema de Mio Cid, value.

Fecha de recepción: 10 de junio de 2010

Fecha de aceptación: 26 de abril de 2011 
Carmen Benito Vessels

University of Maryland

Estados Unidos de Norteamérica

\title{
Valor y crematística: \\ el testimonio del castellano medieval
}

\author{
A Chus, Ángeles y Pepe \\ O fabla con palabra que semeje a tus paños, \\ $o$ viste paños que semejen a tus palabras.
}

BOCADOS DE ORO, 36

La economía, la literatura, la filosofía, la lingüística y la filología han documentado ampliamente el concepto de valor en el lenguaje. Desconozco, sin embargo, la existencia de un estudio de conjunto sobre la axiología en su relación con la lengua; tema sobre el que versará este ensayo, y en el que se prestará especial atención a las expresiones crematísticas en castellano. Tanto el lenguaje como el concepto de valor son metafóricos por naturaleza, pero solo a través de la lengua podemos definirlos y solo a través de ella llegamos a conocer la historia. ${ }^{1}$ Los

\footnotetext{
1 "Cualquier época que quiera conocer su pasado debe enfrentarse con el lenguaje ya que el pasado está contenido en él y frustra todo intento de eliminarlo [...]. [Cuando el lenguaje] es atrapado en los engranajes de un proyecto político, o cuando se vuelve mera herramienta de comunicación, pierde su memoria en la conciencia de los hablantes (aunque su fondo siempre permanezca y amenace con vengarse de
} 
cambios en la expresión del valor en castellano reflejan no solo la historia del pensamiento, sino también los ajustes económicos; incluso, hay quienes defienden que los cambios mismos del lenguaje han afectado a los ajustes económicos y no al contrario.

A fin de orquestar con claridad la amplitud y diversidad de los temas tratados en este ensayo, y a sabiendas de que cada uno de los apartados que aquí esbozo puede y debe ser desarrollado ulteriormente, presentaré, en primer lugar, unas pautas preliminares sobre el concepto de valor y sus acepciones en las disciplinas arriba mencionadas; en segundo lugar, mencionaré los hitos históricos y filosóficos más granados de la cultura crematística en relación con la lengua; en tercer lugar, veremos la importancia de la valoración de la lengua en Bocados de oro, $\mathrm{y}$, finalmente, documentaremos las expresiones crematísticas en el Poema de Mio Cid.

El concepto de valor se vincula primariamente con la economía, y en esta disciplina se distinguen al menos cuatro facetas del mismo: coste, cambio, utilidad y aprecio. Estos cuatro términos se traducen al inglés con binomios cuyo segundo elemento es siempre la palabra value (valor): cost value es lo que cuesta producir cierto objeto; exchange value es la cantidad de objetos que podemos obtener a cambio de otro objeto determinado; use value es el valor de alguna cosa equiparada con la utilidad de la misma y, finalmente, esteem value es el valor definido en relación con la apreciación personal de un objeto o con el grado de dificultad que supone su adquisición (Fraser,

un modo oscuro y apocalíptico), se vuelve pura vacuidad allí donde la proliferación acaba por cercenarle sus antiguas raíces y, en definitiva, es alejado brutalmente de su origen" (Forster, El exilio de la palabra, 101 y 188-189). 
Economic Thought and Language). Este último quizá sea el aspecto más complejo del valor, ya que la apreciación cuantitativa puede ser inversamente proporcional a la abundancia o escasez del objeto en cuestión; tal es el caso del aire, que es valiosísimo pero no cuesta nada. En la economía, no hay, por tanto, un concepto genérico de valor per se y este no depende directamente del costo de producción (Fraser, 104).

El concepto de valor económico aplicado al lenguaje tiene elocuentes defensores y detractores. Así, por ejemplo, Lindley M. Fraser defendió que valor, riqueza y dinero son términos cuya puesta en funcionamiento determina el rumbo de la economía. François Grin es de opinión contraria y arguye que es necesario distinguir entre el lenguaje de la economía y la economía del lenguaje; observa Grin que las palabras no se intercambian en un mercado de valores y no tienen las propiedades económicas básicas; a saber: precio, cualidad, oferta y demanda. ${ }^{2}$ En los casi sesenta años que median entre la obra de Fraser y la de Grin, ha habido estudios destacados sobre la relación entre el concepto de valor económico, la palabra y el pensamiento en la cultura occidental —en todos ellos se menciona el dinero como epítome del valor, y la lengua, que se ha equiparado con el dinero mismo, ha sido considerada como un valor capaz de generar dinero. Planteamientos como los anteriores ponen de relieve que la mayor dificultad en el estudio de este tema estriba no solo en identificar cuál es el tipo de valor que otorgamos al lenguaje —dentro de los muchos que abarca la axilogía —, sino en la necesidad de delimitar las áreas de intersección de los

\footnotetext{
2 "The economic concept of exchange value is sometimes cited by linguists in the belief that words have 'exchange value' (as opposed to 'use value') because speakers 'exchange' words. However, words are not exchanged on a 'market' with identified economic properties and components (price, quality, supply and demand), and, in economics, the observable exchange value essentially means 'price'; the analogy is therefore meaningless" (Grin, Economic Approaches to Language Planning, vol. 121, 38).
} 
principios teóricos que definen el valor: sean estos filosóficos, éticos, económicos, lingüísticos o filológicos.

Universalmente, aceptamos que la forma más eficaz de expresar el valor de un objeto es hacerlo con referencia a una unidad monetaria, de suerte que podamos asignarle una cuantificación a dicho objeto (exchange value). Es obvio, afirma Fraser (145), que también podríamos expresar el valor de cualquier producto con referencia a una fruta o a una casa de campo; de tal suerte, diríamos que un piano cuesta " $x$ " número de naranjas y una casa cuesta " $x$ " número de pianos; pero este sistema daría listas interminables, de ahí que el valor se exprese con referencia a un común denominador: el dinero. A pesar de todo, la historia ha conocido ejemplos de expresiones de valor en términos monetarios que no tenían nada que ver con la moneda usada para la transacción, sino con otros objetos de intercambio; estas instancias fueron posibles gracias a la condición metafórica del valor del dinero y al acuerdo tácito del hablante para aceptarlo como metáfora lingüística. Así, por ejemplo, el cacao fue usado por los aztecas como forma de pago, e incluso conocemos querellas por la falsificación de esta forma de dinero, pues podía vaciarse el contenido de los granos de cacao y rellenar con barro la cáscara hueca. Entre los europeos, la pólvora fue usada como moneda desde los siglos x al XIV, y nos consta también que durante la Edad Media, una misma moneda pudo tener distinto valor en diferentes lugares; con lo cual, idéntico significante, significado y referente no tenían valor real, sino metafórico; tal fue el caso del marco, moneda de origen escandinavo, que se difundió por toda Europa a partir del siglo Ix (Bloch, Esquisse d'une Histoire Monétaire de l'Europe). Asimismo, el lenguaje monetario pasó a ser un lenguaje filosófico; en Francia, por ejemplo, después de la Edad Media, continuó hablándose de sous y, a pesar de que estos ya no existían, seguía vigente el valor que los mismos expresaban. También en España, para diferenciar entre dos monedas, el sueldo de oro y 
el de plata, cuando este último perdió casi todo su valor, aquél pasó a llamarse maravedí. Finalmente, en Europa, la creación de monedas de banco se produjo para solucionar el problema causado por la inestabilidad de la moneda medieval de todos los países europeos; la acuñación más famosa fue el florín de Amsterdam, emitido por primera vez en 1622; pero también el florín pasó a ser una moneda puramente ficticia, con base en la cual se calculaban todos los depósitos y transferencias (Bloch, 84).

En tiempos más recientes, en las transacciones internacionales con la Alemania de la posguerra, las referencias al marco de oro eran, en realidad, alusiones a un marco de oro inexistente, es decir, a un marco de oro previo a la devastadora inflación de mediados del siglo xx (Fraser, 154); también en la Alemania de mediados del pasado siglo, dada la inestabilidad de la moneda, los precios llegaron a determinarse conforme al valor de la mantequilla. En definitiva, aunque históricamente el valor intrínseco de cada moneda comenzó siendo igual a la cantidad de metal precioso que la misma contenía, el valor de cambio, o poder de compra de la moneda, es una noción de orden exclusivamente social y económico que se formula en términos lingüísticos.

Si bien las transformaciones monetarias han ido a la zaga de otras transformaciones sociales, el concepto de valor también ha cambiado a lo largo de la historia y se refleja de modo distinto en diferentes idiomas (Bloch, 11). El español, por ejemplo, ha mantenido un único término para expresar valor (frente a value y worth del inglés) pero ha recurrido a la creación de numerosísimas metáforas crematísticas para precisar sus matizaciones. ${ }^{3}$

${ }^{3}$ Valor se define en español en el Diccionario de Autoridades, como: 1. "la calidad que constituye una cosa digna de estimación ú precio. Es voz puramente latina" 2. "El precio que se regula correspondiente é igual a la situación de alguna cosa. Lat. Valor. Pretium"; 3. "Se toma asimismo por ánimo y aliento, que desprecia el miedo y temor en las empressas o resoluciones. Lat. Virtus. Fortitudo. Animi Praesentia"; 
La traducción de la palabra valor al alemán es complicada, y se puede interpretar como: Kraft, Fähigkeit, Gabe, Geltung, Rang, Ansehen, Stand, Gültigkeit, Wert, Ebenbürtigkeit, Ertrag, Reichtum, Tapferkeit, Mut, Feingehalt y Notenwert ${ }^{4}$ cada una de estas palabras corresponde, al menos parcialmente, a las definiciones anteriormente citadas del Diccionario de Autoridades. La aparente parquedad léxica formal del español y la sobreabundancia del alemán se invierte drásticamente cuando examinamos la complejidad de recursos y la riquísima expresión del concepto de valor en español, y así lo ha demostrado Juan Zaragüeta (El lenguaje y la filosofía, 167 y ss.).

Solo en la numismática podemos decir que el dinero representa dinero, y solo en la filosofía la lengua se distingue del lenguaje de la lengua. ${ }^{5}$ Por tanto, el carácter metafórico del va-

4. "Significa asimismo subsistencia y firmeza de algún acto. Lat. Valor"; 5. "Significa también fuerza, actividad, eficacia, o virtud de las cosas para producir sus efectos. Lat. Virtus"; 6. "Significa asimismo el rédito, fruto o producto de alguna hacienda, de estado u empleo, y así se dan relaciones de valores. Lat. Proventus, aestimatio."; 7. "Se llama también la equivalencia de una cosa a otra, especialmente hablando de las monedas. Lat. Valor".

${ }^{4}$ Respecto al alemán y su evolución, Regina A. Wenzel ha comentado que "The development of the German language [...] underwent significant change in its transition from Middle High German to Early New High German. What is fascinating here is the extent to which linguistic changes coincide with the establishment of a monetary economy, thus suggesting the parallel relationship between these representational systems. The sixteenth century was the most influential period in the formation of New High German. The Reformation and Luther's translation of the Bible (1521-34) led to the establishment of the language of the Saxon Chancery as standard German, while simultaneously efforts were made to make German acceptable as an official language" (Changing Notions of Money and Language in German Literature from 1509 to 1956,50 y 51).

5 "Para Benjamin, hay dos clases de lenguaje: uno cuyo objeto es el mundo y otro que carece de objeto. El primer tipo de lenguaje es la prisión de la necesidad: su obsesión es la manipulación técnica del mundo cuya finalidad es la supervivencia. En el segundo tipo de lenguaje que existe al comienzo y al fin de los tiempos, reside la libertad. La esencia de esta clase de lenguaje es el nombrar. Nombrando las cosas, nos dirigimos no a la cosa nombrada, sino al lenguaje como tal. El nombre incorpora la cosa a la estructura del lenguaje, liberándola de sus prosaísmos, uniéndola a la trascendencia del lenguaje. El objeto del lenguaje es el lenguaje mismo. Esta reflexi- 
lor del dinero, y el hecho de que siempre representa alguna otra cosa, le concede al mismo la capacidad de implementar nuevas estructuras de pensamiento y, por ende, de expresión lingüística (Helm, The Intersection of Material and Poetic Economy, 9). Incluso el cambio físico del dinero, tanto en el soporte material como en su forma, ha tenido un gran impacto en la vida del ser humano; lo cual atañe, naturalmente, a la literatura y a la filosofía. Siguiendo esta línea teórica, Klaus Riegel ha comparado el sistema monetario y el lingüístico a partir de la economía de trueque y concluye que el funcionamiento de aquel es similar al protolenguaje, y que solo cuando el dinero circula en un sistema de aceptación de pagarés (debenture system) podemos hablar propiamente de una comparación entre el dinero y el lenguaje (Helm, 11). Es posible afirmar, por tanto, que hasta la fecha continúa vivo el debate sobre la relación entre el lenguaje, el valor y el dinero, y las metáforas lingüísticas con las que nos referimos a ellos.

En contrapartida, el dinero como objeto útil ("commodity") tiene varias concreciones; las más evidentes son las monedas mismas, el papel moneda, los cheques, las tarjetas de crédito y los pagarés. Pero ninguno de estos soportes materiales del dinero se aprecia por lo que en realidad es en sí mismo (piezas de metal y pedazos de papel o de plástico). El valor supuestamente inherente al dinero depende de la aceptación que este tenga para la persona y del momento socioeconómico en el que se realice la transacción. La prueba más obvia de que el dinero no tiene un valor inherente es que en épocas prósperas, el ahorro de dinero equivale a la acumulación de valor, pero en épocas de elevada inflación, la tendencia general de los usuarios es reducir la cantidad de dinero y utilizarlo como un medio para hacer y recibir pagos, no como un medio de acumulación de valor. Un

vidad libera al lenguaje del prosaísmo de la positividad. Así era al comienzo en el Génesis, así será en el fin" (Forster, El exilio de la palabra,72). 
proceso similar a este es el que sigue el lenguaje para mantener, renovar o eliminar palabras del léxico y actualizar así "su valor comunicativo" (exchange value); o, incluso, puede reducirse un sistema fonológico que no sea "rentable" y sustituirse por otro más eficaz, como ocurrió con la reducción de las sibilantes del castellano medieval.

Contrariamente a las apariencias, ni el dinero ni el lenguaje tienen un valor estable; y también, contrariamente a las apariencias, la volatilidad del valor de la moneda y las lentas y casi imperceptibles matizaciones en la forma y el significado de las palabras contribuyen a promover la economía y la vida de la lengua. Esta paradoja u oxímoron de la "estable volatilidad" del valor - aplicable a las variaciones de los significados lingüísticos - se menciona ya en la Biblia, en la parábola de los talentos (Mateo 25: 15-30), narración en la que se elogia a los dos sirvientes que invirtieron los enigmáticos talentos, aun a riesgo de perderlos, y se recrimina al tercer sirviente, quien los enterró para salvaguardarlos. Es decir, la economía, lo mismo que el lenguaje, crece y se desarrolla gracias a las crisis que supera, y la estabilidad no es en sí misma signo de prosperidad (Lapesa, Crisis históricas y crisis de la lengua española). Pensemos que casi todas las palabras del español moderno fueron en algún momento o bien prevaricaciones del latín tardío, o bien neologismos, barbarismos, cultismos, arcaísmos o préstamos de otras lenguas; no olvidemos que el lenguaje crece con el ser humano y vive en su imperceptible pero continua mutabilidad.

El cambio de valor atribuido a la moneda, o mutación, va unido a los cambios nominales de las piezas en circulación, pero es muy difícil encontrar una respuesta convincente a cuándo y en qué medio social exactamente se produce la alteración del vocabulario. Según Marc Bloch, los cambios lingüísticos representan una profunda transformación de la mentalidad económica que debemos explorar y, como veremos aquí, en castellano 
medieval quedan testimonios fehacientes de estos cambios de mentalidad en los dos textos a los que me referiré: Bocados de oro y el Poema de Mio Cid. ${ }^{6}$ Durante la Edad Media, en la Romania occidental, son muy raras las expresiones de valor, referidas a un intercambio o trueque, en las que se omita la mención a la moneda en curso; una de las escasísimas instancias llamó la atención de Marc Bloch, quien la tomó como ejemplo por su carácter inusitado; se trata de los versos del Poema de Mio Cid en los que los infantes de Carrión, que habían sido obligados a devolver los 3,000 marcos de plata de la dote recibida en las bodas (vv. 3236 y ss.), responden que harían el pago en "apreciatura": corceles, palafrenes, mulas y espadas (Bloch, 30). Este sería un caso extremo en el que el valor crematístico se mide sin aludir a la moneda en curso o a una moneda inexistente - como vimos que ocurrió con el marco de oro alemán, el maravedí español y el sous francés-, sino que se define solo en relación con el concepto filosófico de dinero (apreciatura) y no con el soporte material en el que se concretiza (marco de plata). Este ejemplo del Poema de Mio Cid representa el reverso de lo que tradicionalmente hemos visto; es decir, en la epopeya castellana queda constancia de que el proceso de identificación entre la palabra y el dinero puede realizarse desde el "concepto de dinero" como valor -independientemente de la moneda- y que este existe dentro del lenguaje no solo como "dinero de la mente", sino también como lo que yo llamaría "dinero de la lengua".?

6 "Je l'ignore et je regrette de l'ignorer. Car je crois que ce fait de langage exprime une modification assez profonde de la mentalité économique. On a de plus en plus attaché d'importance à la monnaie materielle — et cette tendance n'a pas eté, de toute évidence, sans répercussion sur la pratique" (Bloch, 42).

${ }^{7} \mathrm{Al}$ "dinero de la mente" se ha referido Marc Shell: "A formal money of the mind informs all discourse and is as unaffected by weather or not the thematic content of a particular work includes money as by whether or not the material content of the ink in which the work may be inscribed includes gold" (The Economy of Literature, 3). 
La idea filosófica del valor aplicada a la lengua no es un resultado natural, sino una construcción ideológica que va unida a la poiesis o capacidad de hacer con la palabra del homo loquens. En la actualidad, en español, hemos perdido la noción de "hacer a través del lenguaje" que estaba implícita en la poiesis griega, $\mathrm{y}$, por supuesto, hemos perdido el significado cidiano de apreciatura, pero estas pérdidas se producen solo en la memoria de la conciencia de los hablantes, no en la lengua misma, y por eso en español continuamos usando expresiones que se sustentan sobre ambos conceptos. Es decir, si aceptamos el valor crematístico del lenguaje, si formulamos expresiones crematísticas, si cambiamos cíclicamente el lenguaje económico y la economía del lenguaje es gracias a que aún pervive la capacidad de hacer con el lenguaje que se definió en la poiesis $\mathrm{y}$, consciente o inconscientemente, buscamos modos de llegar a la paridad lingüística (lo mismo que en la apreciatura) entre los múltiples dominios del valor. Así, por ejemplo, las palabras tacha y mancha pertenecen al área semántica de lo físico, pero son aplicadas al dominio de lo moral para expresar minusvalía.

La riqueza de metáforas crematísticas en castellano demuestra la vigente relación entre el lenguaje y el valor en la economía actual y la axiología. En español, decimos que podemos prestar y tomar prestadas palabras de otras lenguas; el hispanohablante acepta que el significado de ciertos vocablos se devalúa o incluso se pierde. Decimos también que hay falsos cognados; tenemos dobletes lingüísticos; podemos acuñar expresiones, enriquecer nuestro vocabulario, empobrecer un texto, ahorrar palabras o ingresarlas, como bien común, en un tesoro lexicográfico o en un banco de datos. Asimismo, decimos que heredamos nuestra lengua materna; pero la riqueza monetaria y léxica, así como el aprendizaje de otras lenguas, requiere una inversión de tiempo por nuestra parte para lograr fluidez y solvencia. En la vida cotidiana, si aceptamos promesas de pagos o saldos verbales de deudas es porque hemos aceptado que las 
palabras pueden valer su peso en oro, o porque la palabra empeñada puede ser aceptada como pagaré o letra de cambio. En contrapartida, el incumplimiento de pagarés verbales hace que la palabra pase a no valer nada y el individuo pierda su crédito social. La elocuencia y la parquedad lingüística son rasgos definitorios de la persona que se valoran cualitativa y cuantitativamente: hay personas de pocas palabras, otras tienen mucha labia o un pico de oro, pero hay quienes malgastan la lengua, o menoscaban su valor, y su palabra mermada pasa a ser palabrería. Finalmente, podemos usar los términos traslático, traslado y traslaciones para referirnos tanto a una traslación interlingüística como a una transferencia de propiedad.

Las palabras anteriormente destacadas, amén de testimoniar el concepto de valor imbricado en la lengua, revelan que en las unidades básicas del lenguaje de la lengua y de la crematística (la palabra y el dinero respectivamente), los significados dependen de abstracciones fiduciarias, y que estas se basan en el mismo principio que las metáforas lingüísticas. Aceptamos que un papel o una palabra tienen un determinado valor a sabiendas de que un billete de banco, que es solo un pedazo de papel con un número, gráficas y frases inscritas en él, nunca podría venderse por la cantidad de dinero que predica, y que, literalmente, ninguna palabra tiene valor, somos nosotros quienes se lo atribuimos convencionalmente. Entendemos así por qué Marc Shell definió la lengua como "el dinero de la mente" ("the money of the mind") y a raíz de esto desarrolló su teoría sobre la interrelación formal (no de contenido) de la economía, la literatura y la filosofía como campos de conocimiento que adquieren forma a través de la representación simbólica o metafórica. ${ }^{8}$

\footnotetext{
${ }^{8}$ Refiriéndose a la Genealogía de la moral de Nietzsche, dice Shell (The Economy of Literature, 11) que la moderna acuñación y circulación de dinero produjo una revolución económica y verbal, en la cual la genealogía del dinero se debía estudiar desde una nueva lógica: el dinero de la mente: "A fundamental change in price making constitutes a fundamental change in thinking. The development of money was
} 
También en la lingüística se ha estudiado el concepto de valor. En esta disciplina, el valor del lenguaje se mide respecto a su capacidad de representación. Es decir, cuanto más extensa sea el área de significado que abarca una palabra, más alto será el valor de la misma. En el Curso de lingüistica general, Ferdinand de Saussure (1857-1913) relacionó el lenguaje y el valor en estos términos: "Cuando se habla del valor de una palabra, se piensa generalmente, y sobre todo, en la propiedad que tiene la palabra de representar una idea" (194). El valor se diferencia de lo que se llama significación en que: "el valor tomado en su aspecto conceptual, es sin duda un elemento de la significación, y es muy difícil saber cómo se distingue de la significación a pesar de estar bajo su dependencia" (194). Es más, para Saussure:

Como la palabra forma parte de un sistema, está revestida no solo de una significación, sino también, y sobre todo, de un valor. Dentro de una misma lengua, todas las palabras que expresan ideas vecinas se limitan recíprocamente: sinónimos como recelar, temer, tener miedo, no tienen valor propio más que por su oposición; si recelar no existiera, todo su contenido iría a sus concurrentes. Al revés, hay términos que se enriquecen por contacto con otros [...] Así el valor de todo término está determinado por lo que lo rodea (197, énfasis mío).

Claude Lévi-Strauss (1908-2009) también se refirió al valor lingüístico, pero lo hizo desde una perspectiva antropológica en la que subyace la definición saussureana de valor-significación. Lévi-Strauss observó que los europeos y los americanos hablan casi sin cesar produciendo una especie de abuso, o despilfarro del lenguaje; mientras que los hablantes de las llama-

such a change. Although minting was not a great technological innovation, money informed a powerful revolution in economic and verbal media. The genealogy of the money form is the study of a new logic that is the money of the mind". 
das "culturas primitivas" son muy parcos en su uso del lenguaje, ahorran las palabras, no hablan en cualquier momento ni sobre cualquier cosa. Hay en estas culturas una valoración casi sacra del lenguaje y un particular aprecio del silencio; idea que, como sabemos, fue venerada entre los místicos españoles, para quienes el silencio, su significado y la posible interpretación del mismo tenían además de una función, un espacio textual.

El concepto de valor en la lingüística no ha de confundirse con la filosofía del valor en el lenguaje. Esta última no solo refleja, sino que afecta nuestro modo de pensar, y de ello trató Juan Zaragüeta, quien a principios del siglo pasado documentó ampliamente el concepto de valor en el léxico castellano y su relación con la filosofía y la historia del pensamiento español. También Tomás Carreras Artau, filósofo contemporáneo de Zaragüeta, se ocupó del valor del lenguaje; para él, el valor es inseparable de la teodicea, y afirmó que aquel ha de definirse conforme al sentido griego de moral, es decir, como el arte de bien vivir. ${ }^{9}$

La filología nos enseña que el término valor no está documentado en latín clásico y que solo empezó a difundirse a partir de la Edad Media tardía, época en la que valor se refirió exclusivamente a la persona física o a sus potencias espirituales. En el Renacimiento, el valor se estudió junto al precio, pero la expresión "valor y precio" es de uso exclusivamente medie-

9 "El lenguaje ilustra grandemente también acerca del punto difícil de la permanencia y la relatividad de los valores. Hay palabras de sentido moral que no envejecen nunca. Son las que expresan los valores eternos, tales como la bondad, la justicia, la lealtad, la abnegación [...]. Pero hay un conjunto de palabras tipológicas de una existencia transitoria: mueren después de una trayectoria más o menos duradera, a veces fugaz; es decir pierden su sentido, y pasan al panteón de las palabras fósiles [...]. La intuición popular es primaria y de origen; la intuición exaltada ahora por la Filosofía de los Valores es una intuición de vuelta, viene después de un período angustioso de razón pura, es un retorno a la niñez mental" (Carreras Artau, "De los moralistas españoles...", 139). 
val, no renacentista, y se usó como atributo de la persona, no de los objetos materiales. ${ }^{10}$ El filólogo Alexander H. Schutz, en su estudio sobre la expresión "precio y valor" en la Provenza medieval, observó que en los diccionarios más respetados de su época no había una definición uniforme para las palabras tardo latinas que significaban precio y valor ("The Provençal Expression Pretz e Valor", 489). Pero el citado erudito demostró también que en latín medieval el verbo valere sufrió varios cambios, y uno de ellos fue el acercamiento al significado de posse. Una excepción notoria a la ausencia de valere en latín, señala Schutz, es el registro del término valor en la Summa Theologiae, donde valere se ha de entender como eficacia; es decir, la capacidad de producir un efecto buscado. Afirma también Alexander Schutz que en la expresión formulaica "precio y valor" los dos términos constituyentes no siempre son claramente separables: en ella, precio conlleva la idea económica, es decir, una estimación del valor de la persona en un determinado entorno y en determinadas circunstancias, de ahí la expresión "Pretium famae". Precio es, por tanto, mutable y extrínseco; en cambio, valor es el valor básico de la persona, la suma de sus cualidades intrínsecas y no es susceptible de una estimación común. La fórmula "precio y valor", abundante en la lengua provenzal, fue también documentada por Schutz, como atributo de persona, en el Poema de Mio Cid: "con ella ganaredes grand prez e grand valor" (v. 3197).

Barbara Schuchard siguió los datos proporcionados por Schutz, y en un excelente y poco difundido estudio, Valor $\mathrm{Zu}$ seiner Wortgeschichte im Lateinischen und Romanischen des Mittelalters, trazó la diacronía del término valor en la Edad Media europea. Schuchard explica que el origen de la problemática en

\footnotetext{
${ }^{10}$ Las teorías sobre el justo precio de la escuela de Salamanca son quizá las más avanzadas en su tiempo, e incluso se dice que de ellas derivan los conceptos fundamentales de la escuela de Austria. Véase al respecto, Huerta de Soto, The Austrian School...
} 
torno a la definición de valor estriba precisamente en la semántica del propio término. ${ }^{11}$ Observa Barbara Schuchard que ya Pietro Bembo y Benedetto Varchi comentaron que en latín no había ninguna palabra para expresar valor; lo cual provocó gran perplejidad en Bembo y grandes dificultades en su interpretación de textos clásicos. ${ }^{12}$ Afirma también Barbara Schuchard que en los estudios lexicográficos de la Antigüedad Clásica no se documenta la palabra valor hasta el año 600 d. C., y que las tres acepciones dominantes del término en cuestión pueden resumirse en las expresiones léxicas latinas que Du Cange clasificó como tres atributos personales: virtud bélica, gran hazaña y facultad valorativa. ${ }^{13}$ Según demuestra la filóloga alemana, la primera documentación latina del término valor se encuentra en un texto legal visigótico de la diócesis toledana llamado Leges Visighothorum. ${ }^{14}$ Es decir, la palabra valor se difunde en latín tardío y desde el terreno jurídico hispano, el cual estaba vinculado ideológicamente con la Germania medieval. ${ }^{15}$

11 “Aus den einschlägigen Wörterbüchern ergibt sich, da $\beta$ valor im klassischen Latein nicht vorkommt. So that z.B. Georges valor nicht aufgenomen, und auch in den bis zum Jahre 600 n. Chr. Reichenden Sammlungen des Thesaurus Linguae Latinae fehlt es" (14).

12 "In seinem Lob der Muttersprache wundert sich Pietro Bembo, wie man im Latenischen ohne das Wort valor habe auskommen können [...] Auch Benedetto Varchi stellt fest, da $\beta$ valor im Lateinischen nicht existiere" (9).

13 "Du Cange gibt drei verschiedene Bedeutungen an, belegt sie aber mit sehr späten Glossen und Urkunden (12.14.Jh.): 1. 'strenuitas, virtus bellica', 2. 'quidquid emolumenti ex re aliqua percipitur', 3. 'valetudo, facultas'. Die zweite Bedeutung scheint mir im angeführten Beleg auf 'geld — oder Sachwert'hin präzisiert werden zu können" (16).

14 "Die Suche nach dem frühesten Zeugnis hat in die Mitte des 7. Jahrhunderts geführt. Valor begegnet in einem Vortwort des Bischofs Eugenius von Toledo und in den Leges Visigothorum" (18).

15 "Wenn der früheste Beleg aus der Vorrede zur Bearbeitung eines Schöpfungsgedichts des 657 gestorbenen Bischofs Eugenius stammt, so mu $\beta$ das diesser Theorie nicht widersprechen. Eugenius fertig die Bearbeitung nämlich an auf des Gotenkönigs Chindasvintus, und eben in den Gesetzen der Gotenkönige wir das Wort valor im 7. Jahrhundert mehrfach angewandt. Möglicherweise waren Geistliche maßgeblich an der Ausarbeitung der Gesetzesfassungen beteiligt, jedenfalls darf man vermuten, da $\beta$ ein Bischof sie kannte" (19). 
Por tanto, parte del problema para definir el concepto actual de valor, y para identificar el área de intersección de los campos en los que se define el mismo, estriba en que el significado de la palabra valor, ya en latín medieval, dependía de los modificadores adyacentes; ${ }^{16}$ no se podía, ni se puede, hablar de valor en términos absolutos e independientes. El amplio espectro de aplicación del término valor al que nos venimos refiriendo es particularmente manifiesto en la épica medieval, y específicamente, señala Schuchard, en dos textos: el Poema de Mio Cid y la Chanson de Roland. ${ }^{17}$

Los ejemplos del Poema de Mio Cid proporcionados por Alexander H. Schutz, la puntual mención de Barbara Schuchard a esta obra, la documentación identificada por Schuchard en la diócesis toledana, y el ejemplo de pago por apreciatura citado por Marc Bloch son importantísimas llamadas de atención sobre el papel del castellano y del latín hispano en la historia del pensamiento europeo y en el desarrollo de la idea de valor unida al lenguaje. ${ }^{18} \mathrm{Al}$ final de este ensayo proporcionaré otros ejemplos hispanomedievales que amplían considerablemente las sucintas y extraordinarias alusiones sobre el valor en los autores citados.

16 "Die Formelhaftigkeit kommt zustande durch das wiederholte Nebeneinander von valor mit perennis, perpetuus, memoria, constare, consistere, subsistere und obtinere und erinnert an die Formeln aus den Chartae Eichsfeldsenses und Hellenses" (20).

17 "Die Bedeutungen und Anwendungsbereiche sind schon im Spät- und Mittellatein, im Rolandslied und im Cid an Zahl nicht gering” (10). Hoy en día, aunque sin hacer mención a esta filosofía, la crítica se inclina a incluir la axiología dentro de los llamados estudios culturales e interdisciplinarios. Y se prefiere el término "globalización" para referirse, sin mencionarlas tampoco, a las áreas que aquí he identificado como premisas fundamentales para la definición del término en cuestión.

${ }^{18}$ Para los matices del término valor en el Poema de Mio Cid, véase Anales del Instituto de Lingüística (vol. 1, 21). 
La relación de la cultura crematística con la lengua data de tiempos inmemoriales. En la Biblia se compara el valor de la palabra con la propia vida, con el oro y con el dinero: "El que vigila su boca, guarda su vida; el que suelta sus labios, busca su ruina" (Proverbios 13: 3); "Aunque tengas oro y perlas en cantidad, lo más precioso son unos labios sensatos" (Proverbios 20: 15); "Manzana de oro con adornos de plata, la palabra dicha a su tiempo" (Proverbios 25:11). La salvación y la condena del alma se supeditan al lenguaje: "Por tus palabras serás absuelto, y por tus palabras serás condenado" (Mateo 12:37). Y del dinero, considerado como un fin y un bien en sí mismo, se dice que mata la palabra: "La semilla que cayó entre cardos es como el que oye un mensaje, pero las preocupaciones del mundo y la seducción del dinero asfixian el mensaje y queda sin fruto" (Mateo 13:22; y algo similar en Marcos 4:19; y Lucas 8:14).

La usura se anatematiza en la Biblia: ${ }^{19}$ "Si prestas dinero a alguno de mi pueblo, a un pobre vecino tuyo, no te portes con él como un usurero, exigiéndole intereses" (Éxodo 22: 24); “A un hermano tuyo no le exigirás interés ni recargo, sino que dejarás a tu hermano vivir contigo por respeto a tu Dios" (Levítico 25: 36); "No exijas intereses a tu hermano, ni por dinero, ni por víveres, ni por nada de lo que se suele prestar a interés" (Deuteronomio 23: 20); "El que amasa riquezas con interés y

${ }^{19}$ Sin embargo, en sus inicios el término no poseía esta carga negativa. En la Antigüedad se lo asociaba simplemente con el uso de un bien que acarreaba cierta acumulación de valor. Como ha observado Garrán Martínez: "En un primer momento, este término [usura] significó lo mismo que uso, idem est prorsus quod usus. Posteriormente la misma palabra sirvió para designar el aumento cuantitativo que se producía al utilizar un determinado bien. En tal designación se equiparaban las nociones de usura y la de fructus. [...] La primera de estas opciones coincide con el significado el término foenus, entendido este como ganancia injusta percibida por razón del préstamo de un capital. La segunda presenta a la usura como aquel incremento, lícito o ilícito, que se da como consecuencia de un acuerdo de voluntades que tiene forma contractual" (“La concepción del préstamo...", 124-125). 
usura, para el que se apiada de los pobres la acumula" (Proverbios 28: 8), aunque es necesario considerar que el tratamiento de la usura y su relación con la palabra no fue uniforme entre los cristianos, ya que, además del Nuevo Testamento, hay que tener en cuenta los diferentes códigos civiles que no siempre coincidían en las prescripciones. ${ }^{20}$

A pesar de las variantes, la condena de la usura - vista como un negocio que permite el beneficio del prestamista a expensas del prestatario- es compartida por las tres religiones del libro. Entre los judíos, dice Marjorie Grice-Hutchison, las fuentes principales para el tema de la usura proceden del Talmud: Salmos 15: 5; Éxodo 22:25; Deuteronomio 23: 19-20; Ezequiel 18:8-9 y Ezequiel 22:12. La teoría rabínica de la usura está recopilada en el tratado del Talmud llamado Baba Mezi'a, obra en la que los rabinos intentan conciliar las necesidades de los comerciantes con la ley de Moisés. En la tradición islámica, el tratamiento de la usura es similar al expresado entre los judíos, y además existe una prohibición estricta de la usura y de las apuestas. ${ }^{21}$ Además de la faceta estrictamente económica

\footnotetext{
${ }^{20}$ Con todo, para los cristianos hay varios pasajes bíblicos fundamentales en los que se inspira el tratamiento de la usura, aquél en el que Jesucristo vuelca las mesas de los prestamistas en el templo, y el pasaje de Lucas (6:35) en el que se dice que debemos amar a nuestros enemigos, hacer el bien y hacer préstamos sin esperar nada a cambio. Asimismo, los Padres de la Iglesia condenaron la usura vehementemente; destacan entre ellos los escritos de san Clemente (c. 150-211), san Jerónimo (347-419), san Basilio (330-379), san Gregorio de Nicea (c. 335-394), san Ambrosio (339-97), san Juan Crisóstomo (344-407), san Agustín (354-430). Véase, GriceHutchison (Early Economic Thought in Spain 1177-1740, 1-29).

${ }^{21}$ Una contribución fundamental al tema de la usura es el Mishné Torá, o Código de Maimónides, obra destinada a sus correligionarios y en cuyo libro 12, Libro de la adquisición, y en el libro 13, Libro de los juicios, se explicita que la usura está prohibida entre los israelitas, que el prestamista transgrede seis mandamientos y quien pide prestado transgrede dos. Para el judío, a pesar de infringir la ley, prestamista y prestatario no son castigados al azote público, porque la usura es restaurable y hay que distinguir entre usura directa, prohibida en el Pentateuco, y la indirecta, prohibida por la ley rabínica. En cualquier caso, el préstamo entre judíos era obligatoriamente gratuito y la usura solo estaba permitida entre judíos y gentiles. Véase Grice-Hutchison.
} 
de la usura, en las tradiciones judía, musulmana y cristiana del Medioevo, existió un concepto del que hoy apenas queda la sombra y que está directamente relacionado con el lenguaje: la "usura verbal" o "usura espiritual". De hecho, "usura verbal" es un término técnico que para los Padres de la Iglesia, y dentro de la tradición islámica y en el Talmud, se refiere a la generación de un significado ilegal — no natural, según los Padres de la Iglesia- y que se consigue mediante juegos de palabras y adulación (Shell, Money, Language and Thought, 49). La Glossa ordinaria, explica Marc Shell, se refiere a la usura siguiendo la pauta espiritual de la ya mencionada parábola de los talentos (75); y los préstamos, en su modalidad de commodatum (el objeto prestado se devuelve después de usarlo, por ejemplo, una mula), debían ser gratuitos, dice la Iglesia. El Decreto (1139) de Graciano, y las Decretales (1234) de Gregorio IX son las leyes canónicas sobre las que la Iglesia asienta sus rigurosas teorías contra la usura. Y fue san Raimundo de Peñafort (11801278) quien más influyó en la regulación de la misma y quien intentó conciliar o mitigar la severidad de las leyes canónicas con los beneficios de la expansión comercial. La condena de la usura, que no afectaba a los judíos, fue oficial en Castilla en 1348 y un poco más tarde en Aragón (Grice-Hutchison, 52). Aunque no he encontrado documentación fehaciente sobre la condena de la usura verbal, Adriana Gómez se refiere también a que Platón criticó la "usura verbal"; entendiendo esta como la actividad venial mediante la cual los sofistas enseñaban el arte de la persuasión a cambio de dinero (El dinero y las palabras). Y sabemos que Erasmo, en De Lingua, define los pecados de lengua de una forma similar a la que con anterioridad se definió como "usura verbal".

En la Antigüedad, la acepción más elemental del concepto del valor se vincula a la forma concreta y material del dinero, y su historia y relación con el lenguaje ha dejado fiel testimonio en el léxico románico. En latín, moneta $(>$ moneda) quiere 
decir "acuñación" y es también el apodo de la diosa romana Juno, en cuyo templo se acuñaba el dinero. Pero el étimo moneta también está relacionado conceptualmente con la expresión verbal, ya que deriva de monere (de donde procede la palabra amonestar) que quiere decir 'aconsejar o advertir'. Asimismo, la palabra pecuniario y sus derivados, además de referirse al dinero, aluden a ofensas legales que incluyen una multa de dinero. Algo similar sucede con la palabra griega nomisma (vó $\mu 1 \sigma \mu \alpha)$ que significa 'dinero', derivada de nomos (vó $\mu \circ \varsigma$ ), 'ley o costumbre'. Es decir, en las lenguas clásicas se sobreentiende que los cambios en el valor atribuido al dinero dependen solo de nosotros mismos; y tanto monere como nomos aluden a una forma de acuñación verbal (consejo, advertencia, ley y costumbre). Aunque ya Horacio (siglo I a. C.) emparentó el dinero y el lenguaje y se refirió a la "acuñación de palabras", fueron dos obras de Aristóteles, la Política y la Ética a Nicómaco —redescubiertas en el XIII- las que más impacto tuvieron en el pensamiento escolástico medieval referido a la economía y al dinero. En la Ética, Aristóteles defendía que la indigencia, palabra que significaba tanto la carencia de una cosa como la necesidad de ella, era la medida de todas las cosas. Es también en la Ética donde encontramos la observación sobre la palabra griega nomisma y las connotaciones de dicha asociación.

Dentro de la historia de la lengua española, encontramos que las expresiones crematísticas y valorativas del castellano de la Edad Media y Renacimiento se alejan paulatinamente de la especificidad de sus referentes: "non vale un figo" o "vale un vaso de buen vino" son expresiones inteligibles pero ya caducas en nuestros días; en este distanciamiento, el hablante ha mitigado el antiguo concepto cuantitativo de valor y lo ha elevado a un nivel poético que no se percibe como tal. Así, las expresiones anteriores se formularían en el español de hoy como "vale poco" o "vale mucho", sobreentendiendo en ambos casos "vale poco dinero" o "vale mucho dinero"; con lo cual, observamos 
un desliz desde el campo semántico de valor al del precio. ${ }^{22}$ En su trabajo arriba citado, uno de los más influyentes sobre el valor del dinero, la economía y la expresión verbal en castellano en la Edad Media y Renacimiento, Grice-Hutchison (5-7) comenta que la ley de oferta y demanda determinó en gran parte el valor de los bienes materiales; sin embargo, dicha ley no se aplicó al dinero. Y si la función del dinero era, siguiendo la definición aristotélica, servir de medida para el intercambio de

${ }^{22}$ En español moderno ha habido una devaluación de la poiesis en la medida en que hemos despojado al lenguaje de su capacidad de hacer y de comprar; con excepción de la formidable sobrevivencia en la Maragatería, en el reino de León, ya no se hacen contratos verbales: nuestro conocimiento de los nombres no es el conocimiento de las cosas, nombrar ya no equivale a hacer, pero el lenguaje aún mantiene "valor adquisitivo". La valoración del lenguaje en su acepción económica primaria es la que vemos en las recientes publicaciones auspiciadas en España por la compañía telefónica y en las que no hay metáfora posible. Así, en Economía del español, se formula científicamente el potencial valor pecuniario del español, y por un complejo sistema de fórmulas matemáticas, se estiman costos y beneficios relacionados con el uso, difusión, y aprendizaje del mismo: "La preservada cohesión del español —mayor que la del inglés, obligada referencia en tanto que idioma global- es una magnífica baza para potenciar múltiples actividades de economías crecientemente abiertas e internacionalizadas. Su consensuada unidad le proporciona al español una notoria ventaja comparativa en el mercado mundializado" (García Delgado, Economía del español, 19). En esta misma obra leemos: "Aun cuando se le atribuya capacidad de crear valor, ha de reconocerse que la lengua tiene una naturaleza peculiar como bien económico. Cinco son los rasgos específicos que la caracterizan: un bien sin coste de producción; un bien que no se agota con su uso; un bien con coste único de acceso; el valor de uso se incrementa con el número de usuarios y, es un bien inapropiable" (24 y 25). ¡Ni más ni menos, en estas cinco cualidades radica el valor del español! Y, por esta línea de pensamiento continúa dicha teoría en la que se parte de la idea de que las condiciones de producción de conocimiento son similares a las de producción de la lengua: "La generación de una nueva idea (o de una innovación) comporta un elevado coste fijo inicial; pero, una vez producida, el coste variable de su uso (o de su réplica) puede ser próximo a cero. De igual modo, el dominio de una lengua comporta un desembolso inicial que puede ser relevante, pero el coste posterior de usar el idioma, una vez que ya ha sido aprendido, es próximo a cero. Por lo mismo, el coste de acceder a un idioma es para los agentes equivalente a una inversión: una operación única a través de la que se accede a un activo, cuya utilidad se prolonga a lo largo de diversos ciclos económicos. Respecto a otros activos, lo singular de un idioma es que carece de depreciación: no se deteriora con su uso" (30). Todo es, en el estudio del valor, una cuestión de perspectiva cuya maleabilidad depende del punto de vista adoptado en la teoría de valor. 
bienes, tal función solo podía desempeñarse si el dinero tenía un valor estable. En España, afirma Grice-Hutchison, durante el periodo de la Reconquista se buscó denodadamente una forma de evitar la ruina absoluta de los indigentes, pues solo así se podía sustentar el sistema extorsionista de préstamos. De hecho, explica Grice-Hutchison, es posible que sin este sistema, la Reconquista misma no hubiera sido factible; más aún, la cuestión prestamista fue la base para las revolucionarias teorías de la Escuela de Salamanca. En esta última, durante el siglo XVI, teólogos y moralistas debatieron, entre otras cosas, la idea de precio justo basándose en una finísima distinción lexicográfica aplicada a la expresión de valor.

Dentro de la tradición europea, Francis Bacon (1561-1626) se refirió a la palabra como el "dinero de las cosas intelectuales"; y Georg Wilhelm Friedrich Hegel (1770-1831) definió la Lógica como el "dinero del pensamiento". En Advancement of learning (1605), ya Francis Bacon había dicho que las palabras son las monedas corrientes y aceptadas por conceptos al igual que el dinero se acepta como valor: "words are the tokens current and accepted for conceits, as moneys are for values" (libro II, 16. 3). Y Thomas Hobbes (1588-1679), en Leviathan (1651), le concedió a la razón, y a su expresión a través del lenguaje, un papel fundamental en relación con el valor. ${ }^{23}$ En la obra de Hobbes se enfatiza la vinculación entre el lenguaje y el valor monetario, y por tanto en ella se anticipa el gran interés que este tema despertará en la Europa de los siglos subsiguientes. Para Hobbes, los nombres eran signos arbitrarios y pura invención del hombre, y no las consecuencias de las cosas — como lo fueron en la Edad Media—. ${ }^{24}$ Señaló también

23 "The faculty of reasoning being consequent to the use of speech, it was not possible but that there should have been some general truths found out by reasoning as ancient almost as language itself" (Hobbes, Leviathan, 4).

24 "They are therefore no names of things, but signs, by which we make known that we conceive the consequence of one name or attribute to another" (Leviathan, 
Hobbes varios abusos del discurso o del lenguaje vinculados al valor, a saber: el registro erróneo de los pensamientos por la inconsistencia del significado (valor) que el hablante dé a las palabras; el uso metafórico del lenguaje, ya que toda metáfora desvía el pensamiento e induce a engaño; la mentira — que es en sí misma un fraude- - y, finalmente, la agresión o daño verbal, que es la peculiar forma que el hombre usa para perjudicar a sus congéneres. ${ }^{25}$ El lenguaje tiene pues para Hobbes un valor ético y económico, ya que la verdad y la falsedad pueden ser consideradas atributos del discurso, no de las cosas. Concluye Hobbes que donde no hay lenguaje, no hay verdad ni falsedad; que la verdad nada más consiste en el ordenamiento correcto de los nombres y que esta solamente es viable a través de nuestras afirmaciones (41).

En la Europa del siglo XVI se atribuía especial valor a la lengua por ser esta un símbolo de las cosas y, como tal, un espejo del mensaje divino inscrito en el mundo (Wenzel, Changing Notions of Money, 4); pero en los siglos XVII y XVIII se produjo un cambio fundamental en cuanto al punto de vista sobre el mundo, las creencias y la naturaleza del lenguaje. Se abandonó el concepto de imitación o semejanza en aras de la representa-

11). "The first author of speech was God himself, that instructed Adam how to name such creatures as he presented to his sights, for the Scripture goes no further in this matter. But this was sufficient to direct him to add more names as the experience and use of the creatures should give him the occasion, and to join them in such manner by degrees as to make himself understood [...]. I do not find anything in the Scripture out of which, directly or by consequence, can be gathered that Adam was taught the names of all figures, numbers, measures, colors, sounds, fancies" (37). "The general use of speech is to transfer our mental discourse into verbal, or the train of thoughts into a train of words [...]. The first use of names is to serve for marks or notes of remembrance. Another is when many use the same words to signify, by their connection and order, one to another, what they conceive or think of each matter $[\ldots]$. And for this use they are called signs" (38).

25 "For seeing nature has armed living creatures, some with teeth, some with horns, and some with hands, to grieve an enemy, it is but an abuse of speech to grieve him with the tongue, unless it be one whom we are obliged to govern, and then it is not to grieve but to correct and amend" (Leviathan, 39, cursivas mías). 
ción misma, y comenzó a prestarse especial atención al modo de representar y no a la cosa representada. Empieza así a valorarse la naturaleza dual del signo que es, por una parte, la cosa que representa y, por otra, alude a la cosa representada. ${ }^{26}$ Llegados al siglo XIX se pensó que, al igual que el lenguaje, el papel moneda no solo tenía la capacidad de representar la realidad y el valor del metal noble sino que, casi de forma mágica, podía incrementarlo.

Entre los economistas del siglo xx que se han inmiscuido en el mundo de la lingüística, se ha definido el dinero no por lo que esencialmente es, sino por sus tres usos básicos: a) como intermediario para el intercambio o forma de pago; b) como índice de comparación entre los bienes a intercambiar, o medida de valor; $\mathrm{y}$, finalmente, c) como acumulación de valor. Principios que los economistas consideran también aplicables a la lengua, pues se espera que la comunicación proporcione un mensaje y este se valora por su efectividad, pues lo comunicado enriquece el conocimiento que acumulamos (Vilar, A History of Gold and Money, 19 y 20). Asimismo, en el uso del dinero y en el de la lengua, los economistas consideran que es necesario distinguir entre "medida" y "expresión". En el siglo xx, la materialidad del dinero y los aspectos físicos del signo lingüístico han despertado tanto interés como la faceta etérea e inasible del concepto filosófico y filológico del valor. El filósofo italiano Bruno Leoni (1913-1967) intentó establecer un paralelo entre el dinero y el lenguaje a partir de las similitudes entre la producción, intercambio y falsificación de moneda y palabra. Como sabemos, toda falsificación monetaria se realiza con la intención de engañar a aquel a quien se dirige un pago, pero lo mismo puede

26 "Language itself was no longer a substantial phenomenon, the text one was reading was seen as mere superficiality in the service of representation of meaning: verbal signs became discourse without intrinsic value (rather than, as in the sixteenth century, being regarded as valuable in their role as the carrier of the divine message), mere tools of the human in the search of truth" (Wenzel, 6). 
ocurrir con la falsa traducción de un mensaje de una lengua a otra ("usura verbal"). En el lenguaje y en la economía, la falsificación es posible porque existe dentro de ciertos límites en los que hay un mínimo de significados comúnmente aceptados en el proceso lingüístico y monetario respectivamente. El embaucador usa para beneficio exclusivo el valor común que le atribuye quien recibe la moneda falsa al valor del dinero legal, y esto mismo ocurre cuando alguien usa deliberadamente un lenguaje falso o engañoso (Rossi-Landi, Studi in Onore di Emilio Betti, vol. I, 186). ${ }^{27} \mathrm{La}$ afinidad entre el valor económico y el lingüístico, y hasta cierto punto su interdependencia, permitieron la elaboración de teorías, como las de Leoni y RossiLandi, para quienes una comunidad lingüística es una suerte de gran mercado en el que las palabras, expresiones y mensajes circulan como objetos útiles o "commodities". Por otra parte se ha señalado el abuso de la terminología propia de la economía que algunos teóricos, como Pierre Bourdieu (1930-2002), cuyos presupuestos se basan en los estudios de Rossi-Landi, han aplicado al estudio del lenguaje. En L'économie des échanges linguistiques, Bourdieu habla de la lengua en términos de "mercado", "bienes de consumo", "capital", "beneficios", etc. La mayoría de las veces esto es simplemente una metáfora que

\footnotetext{
27 "Those who use a false and deceptive language can do so only on the condition that they exploit (to their own exclusive advantage) the common meaning that those who listen will mistakenly attribute to the same word when used by the deceiver and the non-deceiver [...] The same thing happens when someone proposes a relatively new use of a word; he will succeed, i.e., be listened to and understood, only if he respects, at least within limits, the meanings already in use for the word he proposes, or at least the meanings already in use for the words he uses to define his word, which can be compared to the metals making up the alloy used in minting a new coin. In short, the common and relatively permanent element in language, or respectively, in money permits a quantity of operations which would seem to have nothing to do with this common element, or actually to refute it, and which, if considered superficially, might lead us to think that nothing generally common existed among the various currencies on the one hand and the various languages on the other, there being infinite currencies and infinite languages" (Rossi-Landi, 186-187).
} 
no dice nada sobre el "valor de la lengua", sea en términos axiológicos o económicos.

\section{III}

Desde la Antigüedad, el oro ha sido la medida universal para determinar el valor de la moneda y, aunque a veces haya coexistido con otros medios, con respecto a él se han definido la riqueza y el concepto de valor por antonomasia; de ahí que la escasez o abundancia de oro fueran decisivas en el desarrollo cultural de Occidente. ${ }^{28}$ Durante la Edad Media europea, con la expansión del cristianismo, se cultivó la forma de relacionar físicamente el lenguaje con el oro a través de la crisografía, o escritura en tinta de oro - chrusos significa dinero y oro(Shell, Money, Language and Thought). Esta técnica fue una práctica común entre cristianos, musulmanes y judíos, quienes, a pesar de sus divergencias culturales, coincidían en la altísima valoración del libro como objeto material. ${ }^{29}$ Asimismo, la dis-

\footnotetext{
${ }^{28}$ Agradezco a Clara Estow su generosa ayuda con este trabajo sobre el valor y espero ávidamente su próxima monografía sobre el oro; la cual, me consta, será fundamental para los investigadores en este tema. No entro aquí en la compleja investigación sobre el oro, sino que apenas me referiré a la idea de valor asociada con la palabra "oro" y a la equiparación del oro con la lengua o con el dinero. Un buen ejemplo lingüístico de la equiparación del oro con el dinero en la cultura occidental es la palabra alemana Geld (“dinero"), que está relacionada etimológicamente con Gold ("oro"). Según Wenzel, cuando el Gold se hace Geld lo que tenemos es un proceso inverso de alquimia, rebajamos el oro. Dada su proximidad fonética, en la cultura germana se equiparan Gold y Geld, pero estas dos palabras, en realidad, no proceden del mismo étimo: Geld ("dinero y moneda") deriva del alto alemán gëlt ("recompensa, ingreso, dinero") y del verbo gëltan ("pagar, recompensar"), que es un cognado del antiguo sajón gildan, término del cual deriva el inglés yield. En cambio, la palabra Gold, deriva del participio de ghel ("ser amarillo"), que en antiguo alemán se decía golt(d) y en alemán actual se dice gelb. Esta misma relación entre el oro y su color se daba en sánscrito, lengua en la que hiranya ("oro") deriva de hári ("oro amarillo") (Wenzel, Changing Notions of Money, 148).

${ }^{29}$ La posesión del libro era en sí un gran privilegio, unido a veces a lo milagroso. Recoge Fernando Gómez Redondo la historia de Tajón, obispo de Zaragoza quien, en sueños, recibió la milagrosa visita de san Gregorio para ayudarle a encontrar en
} 
cusión sobre la relación entre el lenguaje y el dinero proporcionaba a las tres culturas del libro un enemigo común, ya que "el oro qua dinero" es la lengua del diablo (Shell, 191). ${ }^{30}$ Ya en el siglo III a. C. se había practicado la crisografía, cuando se tradujo el Pentateuco al griego; en aquel entonces se prohibió en las sinagogas el uso de rollos crisográficos de la Torá; y en el antiguo Tratado de los escribas se debatían pormenorizadamente las implicaciones intelectuales y espirituales de escribir en oro (191). Amén de las obvias razones económicas de producción, existía una razón ética para la prohibición de escribir en oro, pues quería evitarse que el valor monetario de los documentos interfiriese con el valor del contenido espiritual; se consideraba que al llamar la atención hacia sí mismas, las letras de oro actuaban como impedimenta para la interpretación de la palabra; se advertía además que el aura del oro no debía competir con la aureola de Dios, aunque, paradójicamente, tanto aura como aureola y oro derivan del mismo étimo: auru (191).

\footnotetext{
Roma sus Moralia de Job. San Gregorio le indicó la arqueta y el armario donde tal volumen se hallaba. El libro mismo podía tener propiedades milagrosas, y Redondo da dos ejemplos de ello, tomados de la Estoria de España. En el primero se dice que en la biblioteca de Alejandría "non se quemaron los libros por muchos buenos dichos de castigos et de exiemplos que auie en ellos, et el saber de las antigüedades que era muy noble cosa et non quiso Dios que se perdiesse" ( $E E$ I, 83b, 48-52). En el segundo ejemplo se cuenta de un libro que dio un salto fuera de la hoguera delante de Alfonso VI, ya que en él se contenía el oficio Toledano: "Mientras que el libro dell officio frances quexauase con el fuego et queriese apegar a el" ( $E E$ II, 543 a, 3233). Libro se refería al volumen de hojas de papel o vitela, como hoy lo conocemos, y también se usaba "para definir el marco ordenador de un cierto contenido textual, acepción compartida con palabras de la misma familia como librete o libriello" (Gómez Redondo, "Terminología genérica en la Estoria de España alfonsí', 59).

${ }^{30}$ Véanse también para este tema, las siguientes obras citadas por Shell: Martin Luther, Tischreden, 6 vols. (Weimar, 1912-21), vol I, no. 391; Tractate for Scribes 1.8, in The Minor of the Talmmud, ed. A Cohen (London, 1966). Según M. Shell, la primera referencia a la crisografía aparece en Aristeas Judaeus (ed. P. Wendlannd, Leipzig, 1900, 176), cuando Tolomeo Philadelphus pidió que tradujeran el Pentateuco al griego y el Patriarca de Jerusalén le envió un rollo de la Torá escrito en letras de oro.
} 
Aunque en las tres culturas del libro la crisografía es la conexión más obvia entre escritura y valor, la ponderación de la palabra como bien común y como fuente de riqueza es también un tema compartido por judíos, cristianos y musulmanes. La palabra oro es parte del título de la obra que a continuación veremos, Bocados de oro, pero en ella no se habla de este metal precioso. Sin embargo, el valor del que sí se habla extensamente en Bocados de oro, y que se trata como si fuera oro, es el que deriva o está contenido en la lengua. Este tratado sapiencial fue divulgado en lenguas semíticas y en el siglo XIII adquirió nueva vida en castellano. La gran difusión de Bocados de oro en las tres culturas del libro es quizá uno de los mejores indicadores de la existencia de valores comunes respecto a la filosofía del lenguaje. ${ }^{31}$ A decir de Gómez Redondo, la obra se halla atrapada en un laberinto de lenguas: en primer lugar, es una traducción literal de un original árabe del siglo xi redactado por Abū 1-Wafā al Mubashshir ibn Fātik (1010-1097), médico y filósofo sirio, quien, a su vez, había tomado los modelos de la Antigüedad clásica a través de la obra de Diógenes Laercio. La versión castellana fue traducida al latín en el siglo XIII por Giovanni de Procida en el Liber philosophorum moralium antiquorum. Aunque en castellano solo conservamos dos manuscritos del siglo Xv, se supone que existieron al menos nueve versiones en esta lengua. Bocados de oro se imprimió en Sevilla en 1495, y a esta edición se le añadieron siete capítulos introductorios; a partir de lo cual podemos comenzar a hablar de dos redacciones: a) la llamada Bonium (en la que el conjunto de los epígrafes cuenta el viaje del rey Bonium a la India), y b) la que se atiene al modelo primigenio de la traducción y que debe ser denominada Bocados de oro. Dos son también las fechas que se han propuesto para la traducción de este tratado: 1260 (H. Knust) y 1280 (M. Crombach).

${ }^{31}$ Los datos que siguen proceden de Gómez Redondo, Historia de la prosa medieval castellana, vol. 1, 455-470. 
La apreciación del contenido de Bocados de oro, afirma Gómez Redondo, es manifiesta en el título de la obra, y la explicación de la enigmática palabra "bocados" aparece en la Partida primera de Alfonso X. Aunque bocado, o mordisco, en español medieval se dice muesso - procedente de morsus que es el participio pasado de mordere-, el Rey Sabio define bocado del siguiente modo: "E déstas razones fue fecho el Credo in Deum, a que llaman symbolum, que quiere tanto decir como 'bocados'. E esto es porque cada uno de los Apóstoles por sí dixo su palabra cierta, como creían, e ayuntadas en uno, es ý toda la creencia complida" (I-iii-1, fol. 14vb, apud Gómez Redondo, 457).

Este tratado sapiencial ha sido definido como una obra de excepcional exaltación monárquica que captó también el interés del siglo xv, periodo en el que, lo mismo que en la época alfonsí, "se escribe para dar sentido a un mundo que comienza a girar en torno a la 'palabra' como máximo exponente de la realidad cortesana" (Gómez Redondo, 458). La defensa de los retóricos, versificadores y gramáticos (epígrafes 13 y 14 dedicados a Aristóteles y a Alejandro) constituye el núcleo esencial del libro. El valor de la palabra es indiscutiblemente uno de los temas fundamentales de Bocados de oro, y a él se dedican los capítulos de Hermes, Tad, Solón y Diógenes el Canino.

Que fuera el Rey Sabio quien auspició la traducción de la obra, que dos de los temas centrales del tratado sean el ensalzamiento de la monarquía y la apreciación del lenguaje, y que en su reinado se produjera una enorme revolución lingüística y numismática son hechos que, a la luz de los datos presentados en los preliminares de este ensayo, no pueden pasar inadvertidos. ${ }^{32}$ Fue además en el periodo alfonsí, con el apogeo de las leyendas del Santo Grial, cuando se produjo lo que Shell ha llamado la transición del realismo al nominalismo económi-

${ }^{32}$ Para los grandes cambios monetarios de la época alfonsí, véase Argüello, $M e$ moria sobre El valor de las monedas de D. Alfonso el Sabio. 
co; en este último se le concedía prioridad al intellectus significante sobre la res material. Con las teorías nominalistas, la idea intelectual (dinero) se separó conceptualmente de la cosa real (lingote), de tal suerte que el valor intrínseco del dinero se separó del dinero contante (Shell, Money, Language and Thought, 40). Es una extraordinaria coincidencia que Alfonso $\mathrm{X}$ definiera bocado como symbolum o palabra cierta, y que Marc Shell hablara del lenguaje y del dinero como símbolos, pues, según Shell, la distinción entre sustancia y sombra, en las teorías estéticas y monetarias, afecta la comprensión de la simbolización en general, y de la representación lingüística en particular. ${ }^{33}$ Es decir, el símbolo (o bocado) de oro es una feliz acuñación metafórica del castellano alfonsí que coincide casi literalmente con la analogía entre el símbolo lingüístico y el dinero como símbolo formulada por Shell.

La relación de sentencias sapienciales que ofrezco a continuación habla por sí misma de la importancia que tiene el valor de la lengua en esta obra y, por ende, de la preocupación que existe al respecto en el periodo en el que se redacta. En mi opinión, Bocados de oro expresa de una forma primaria, concreta y eficaz, que el valor en el sentido axiológico más amplio se define con base en la relación conceptual entre el dinero y el lenguaje. Estas sentencias ejemplifican la filosofía del valor (como arte de bien vivir); apuntan hacia la potencial usura verbal; explicitan la acumulación de riqueza amparada en la

\footnotetext{
33 "The distinction between substance and shadow in monetary and aesthetic theory affects the understanding of symbolization in general and of linguistic representation in particular. With the advent of paper money certain analogies, such as 'paper is to gold as Word is to meaning', came to exemplify and to inform logically the discourse about language. For example, critics called for a return to gold not only in money but also in aesthetics and language. Thus Emerson wrote that 'a man's power to connect his thought with its proper symbol, and to utter it' is corrupted when 'new imagery ceases to be created, and old words are perverted to stand for things which are not; a paper currency is employed, when there is no bullion in the vaults"' (Shell, Money, Language and Thought, 18 y 19, subrayado mío).
} 
lengua, ponderan la autosuficiencia del lenguaje como moneda; $y$, en fin, dan forma literaria a los argumentos sobre el valor presentados en este ensayo. ${ }^{34}$

"Con el ordenamiento de la palabra se mantiene la ley, e /8d/ por el mantenimiento de la ley se mantiene el regnado, e por el [mantenimiento del regnado] se puebla el mundo"

(Capítulo de los castigamientos de Tad, Crombach, 18).

"El sesudo es el que retiene su lengua"; "Quando el coraçón es seguro, pasce la lengua"; "La catadura muestra lo que yaze en el [coraçón], más que la palabra"

(Capítulo de Homero, bajo el epígrafe:

"Estas son las palabras de Omero", Crombach, 21).

"Non ha cosa más vil que la mentira, e non ha bien ninguno en ome mintroso"

(Crombach, 23).

"E preguntaron-le: ¿Quál es la más grave cosa en el omne? E dixo: Que conosca lo que es en él, e que guarde la su poridat, e de non fablar en lo que non ha de fablar, e de se non quexar por que non alcanza lo que puna de aver" (Crombach, 24); "E preguntaron-le: ¿Quál es la cosa que es más aguda que espada? E dixo: la lengua de mal ome"

(“Capítulo de Solón”, Crombach, 24).

"E avié escripto en el su sello: El mal que non dura es mejor que el bien que non dura. E avíe escripto en la su cinta: Por el callar es ome seguro de se non arrepentir" (Crombach, 32); "Los más de los males contescen a los animales por que non fablan, e contescen al ome por que fabla" (Crombach, 35); "E cató a un ome que vistíe nobles paños e errava en su palabra, e dixole: O fabla con palabra que semeje a tus paños, o viste paños que semejen a tus palabras" (Crombach, 36); "La buena palabra es el mejor sahumerio que vos podedes dar /16b/" (Crombach, 38); "Antes que fables de Dios, faz las obras que plazen a Dios" (“Capítulo de los fechos de Pitágoras", Crombach, 38).

${ }^{34}$ Sigo la edición de Crombach (Bocados de oro). 
"Non fables ante ningunt ome fasta que oyas la su palabra, e que sepas que comparación ha entre lo que en ti ha de saber e lo que en él. E si fallares a él mejoría, calla-te, e puna de ganar algo d'él; e si tú ovieres mejoría, estonce fabla lo que quisieres" (Crombach, 42); "estava dióginis con unos omes, e calló mucho, e dixieronle: ¿Cómo non fablas conusco? E dixo: la fuerça del ome buena es en las orejas, e la fuerça del otro buena es en su /18a/ lengua" (Crombach, 43); "E oyó a un ome que fablava mucho, e dixo: Paga a tus orejas, que por eso te pusieron dos orejas e una boca, porque oyas más de lo que fablas"

(“Capítulo de Diógines el Canino", Crombach, 43).

"Quien te muestra una palabra de sapiencia, grant bien te faze, e mejor cosa te da que aver" (Crombach, 53); "La fabla es en poder del omne mientra non la dixiere, e después que la dixiere, salle de su poder" (Crombach, 59); "El que ha poder de non fablar, si non en su lugar, mayor poder ha de non fazer ningunt fecho, si non /25a/ en su lugar"; "El fablar es llave del mal, e el callar es cerradura d'él"; "El callar es bueno en los más de los lugares, e el fablar es malo en los más de los lugares"; "Si el ome fabla, es conocido si es conplido o menguado. E si calla, es en dubda"; "El que sabe que ay otrie que cate la su palabra, mejor es que la cate él mesmo, ante que ge la cate otro"; "E dixo a un su discípulo: la palabra contada es sobre ti; pues puna en la decir derecha mente, si non, más vale que te calles"; "El que se duele por la palabra, es seguro de non ser ferido"; "El que calla, cata las palabras de los otros; e el que fabla, catan-le los otros su palabra" (Crombach, 60); "Non he cuidado, por no ser la mí palabra creída; mas he cuidado de non ser derecha" (Crombach, 64); "La lengua es al sesudo castillo, con que se defienda de las vilezas; e al necio es carrera para ellas" (Crombach, 67); "lo que tienes en tu alma, non lo demuestres a cada uno. Que fea cosa es esconderlos omnes sus averes en sus casas, e mostrar lo que tienen en sus coraçones"

(Capítulo de Sócrates", Crombach, 70).

"E la vileza del seso del ome es conocida en fablar mucho en lo que le non aprovecha, e en decir nuevas de lo que non fue demandado nin preguntado"

(“Capítulo de Platón”, Crombach, 80). 
"El festinamiento de la palabra faze errar aina"

("Capítulo de Aristóteles", Crombach, 111).

Con excepción de la morfosintaxis, todas las máximas aquí citadas son de plena actualidad. Podríamos decir que, desde la Edad Media hasta hoy, no ha habido un cambio sustancial respecto al concepto de valor de la lengua, pero sí lo ha habido respecto al concepto y a la expresión del valor en otras áreas como la crematística; hecho que constataremos en la siguiente sección sobre el Poema de Mio Cid. ${ }^{35}$

\section{IV}

Para terminar, en las páginas que siguen aporto algunos datos que quizá ayuden a explicar la problemática planteada por Bloch; es decir, cómo interactúan los cambios nominales referidos a aspectos pecuniarios que se dieron en el medioevo en su relación con los cambios ideológicos. Conviene señalar, en primer lugar, que la cultura crematística y el bimetalismo pecuniario de la Edad Media castellana perviven en español moderno: decimos hoy "hablar en plata" y "escribir en letras de oro"; en cambio, no aceptamos las expresiones "escribir en plata" y "hablar en oro" porque, aunque el hablante ya no tiene conciencia de ello, la plata y sus derivados podían usarse para la iluminación de manuscritos, pero solo la crisografía requería el oro en la escritura. La pervivencia de expresiones en las que se homologa la palabra con los metales nobles es un tema que merece especial atención porque el léxico es siempre índice del pensamiento y de las prioridades de toda comunidad lingüística, incluida la economía. ${ }^{36}$ Grice-Hutchison llamó nuestra atención

\footnotetext{
${ }^{35}$ Sigo la edición de Michael.

${ }^{36}$ Platón ya advirtió el peligro que supone ignorar o fiarse ciegamente de las relaciones entre las categorías lingüísticas y económicas. Marc Shell traza la relación entre el pensamiento lingüístico y económico en otros filósofos que han marcado el
} 
hacia el hecho de que el pensamiento económico medieval no fue uniforme y que son muchas las derivaciones del pensamiento aristotélico en lo referido a la riqueza, al dinero, al valor, al precio y a la usura.

Tomemos como referencia tan solo tres palabras (dinero, sueldo y salario) para ver cómo se diferencia el español del francés en la expresión crematística y valorativa; y cómo, a la vez, dichas diferencias se explican por la historia de la evolución de la moneda y reflejan la historia del pensamiento ${ }^{37} \mathrm{El}$ español medieval eligió la palabra dinero, derivada de denario (moneda de plata), para referirse a las monedas en curso con las que se efectuaban pagos y transacciones comerciales; en cambio, el francés prefirió expresar este concepto con la palabra argent, que significaba tanto dinero como plata. Asimismo, la retribución laboral se expresó tempranamente en español con las palabras salario, derivado de sal, que era la especia en la que en la Edad Media se pagaban ciertos servicios, y sueldo, derivado del nombre de la moneda romana de oro llamada solidus. ${ }^{38} \mathrm{El}$ francés, en cambio,

pensamiento occidental como Hegel, Arthur Shopenhauer, Immanuel Kant o David Hume, quien, por ejemplo, pensaba que las lenguas son establecidas por convenciones humanas, y que lo hacen sin una promesa de futuro; decía también que las lenguas, como el oro y la plata, se convierten en la medida común de intercambio y se aceptan como forma de pago suficiente por lo que en realidad es cien veces su valor ("On the Origins of Justice and Property", en David Hume's Political Essays, apud Shell, Money, Language and Thought, 110). Muchas de estas ideas son rastreables en la literatura y la historia del pensamiento españoles. Así, por ejemplo, la idea del precio justo que algunos estudiosos consideran acuñada en el siglo XVI por los escolásticos de la Escuela de Salamanca, es también discutida por otros filósofos estudiados por Shell (144), entre ellos: Kant en "¿Qué es el dinero?” (Principios metafísicos del Derecho, 1797) y Fitche en su "Teoría del correcto intercambio" (El estado comercial cerrado, 1800).

${ }^{37}$ En francés, se ha estudiado con detalle el impacto de las metáforas crematísticas en los Lais de Marie de France y en Rabelais.Véanse Ponziano Lavatori, Language and Money in Rabelais, y Fitz, "The Prologue to the Lais de Marie de France...", 558-564.

${ }^{38}$ En la Edad Media castellana se acuñó también un sueldo de plata y el de oro pasó a llamarse "maravedí". Y el concepto de "sal" como valor o fuente de riqueza tiene incluso un antecedente bíblico: "vosotros sois la sal de la tierra". 
aunque también adoptó el término salaire, derivado asimismo de sal, relegó la palabra sou (derivado de solidus) para referirse a una moneda de poquísimo valor (sou) o para indicar la carencia de dinero (n'avoir pas un sou); este cambio semántico y la diferenciación entre el francés y el español para expresar la compensación salarial se hizo más notoria con la inclusión de un nuevo término en castellano, la palabra jornal (derivada del fr. journal, o medida agraria derivada de jour) que, en castellano, originalmente era la compensación económica recibida por un día de trabajo en el campo. Asimismo, en castellano medieval, la idea de minusvalía o carencia pecuniaria contenida en la palabra francesa sou se expresa adjetivalmente en el Poema de Mio Cid con el binomio dinero malo (y no dinero falso). Nunca se habla en el Poema de Mio Cid solo de dinero, es decir, el dinero en sí tiene valoración neutra, y el determinante "malo" puede interpretarse en el sentido moral de "pernicioso" o en el sentido económico de "escaso valor": "non les diesse mio Cid de la ganancia un dinero malo" (v. 165).

Independientemente de los resultados, la mencionada selección léxica en francés y en español, y la pervivencia de argent en francés y de dinero en español, son el fruto de la cultura numismática de la Edad Media, época en la que la Península Ibérica mantuvo la acuñación de monedas en plata y oro, mientras que en Francia se abandonó muy pronto el bimetalismo heredado de Roma y solo la plata fue el metal de los "haberes monedados". 39

La vinculación del léxico con la economía en el Poema de Mio Cid se refleja tanto en las metáforas lingüísticas como en el léxico común, ${ }^{40} \mathrm{y}$, como bien dijo Shell, el dinero "habla

\footnotetext{
${ }^{39}$ Por razones obvias, en las áreas circunvecinas al Río de la Plata empezó a usarse el término plata como sinónimo de dinero y desde allí se difundió por toda la América Latina.

40 "That Money and language are complementary or competing systems of tropic production and exchange suggests that money not only is one theme, metaphoric
} 
en y a través del discurso". Desde la Edad Media hasta nuestros días, la fluctuación del concepto del valor en general, y de valor del dinero en particular, y la expresión metafórica del mismo han producido cambios considerables de significado de las palabras. Por ejemplo, la expresión medieval "estar pagado" ya no significa "estar alegre, contento, agradecido o satisfecho", sino que en español actual equivale a "haber sido remunerado"; y recaudar ha de interpretarse como "guardar bien" en la expresión "Gran recabdo" (v. 24), y hoy en día el verbo recaudar significa solo "recoger o recopilar" y se aplica primariamente a aspectos económicos o cuantitativos como "recaudar dinero"; pervive, sin embargo, la expresión "guardar a buen recaudo"; explicar las causas de estos cambios es tema harto difícil; sin embargo, sí podemos calibrar con un margen mínimo de error algunos aspectos de los cambios cuantitativos que inferimos de esta expresión. Es decir, la abundancia de términos relacionados con la crematística y el valor en el Poema de Mio Cid refleja las condiciones sociales en las que se forjó la mentalidad de la comunidad lingüística castellana medieval. La escasez de bienes suntuarios en la Edad Media castellana potenció el valor de los mismos y, lejos de ser nimio, el carisma que implicaba su adquisición se refleja en expresiones de altísima frecuencia como la ya mencionada, "estar pagado". El crecimiento de las actividades económicas y la expansión de la economía desde fines de la Edad Media requerían también un cambio lingüístico; este es, por tanto, una consecuencia del desarrollo económico (Coulmas, Language and Economy). También en Francia, particularmente en Provenza, vimos ya cómo la expresión "valor

content, or 'root metaphor' in some works of language, but also participates actively in all. My argument is not that money is talked about in particular works of literature and philosophy (which is certainly the case), but that money talks in and through discourse in general. The monetary information of thought, unlike its content, cannot be eradicated from discourse without changing thought itself, within whose tropes and processes the language of wares (Warensprache) is an ineradicable participant" (Shell, Money, Language and Thought, 180 y 181). 
y precio" tuvo una altísima frecuencia de uso y esta se relacionaba directamente con los cambios económicos conocidos en dicha región.

Dentro del ámbito peninsular, y contrariamente a lo que muchos historiadores defienden, la idea de "hacer dinero" no fue ajena al hombre medieval, sino que fue ampliamente fomentada durante la guerra de la Reconquista (Moss y Ryan, Economic Thought in Spain). Observó Marjorie Grice-Hutchinson que el mejor ejemplo de esta mentalidad lo encontramos en la obra más emblemática de la épica española, el Poema de Mio $C i d$. En este texto, resulta abrumadora la magnitud de las riquezas adquiridas por Rodrigo Díaz y sus vasallos; tanto es así que la adquisición y donación de bienes connotan un estatus casi regio para el vasallo de Alfonso VI. Joseph Duggan ha pormenorizado la riqueza obtenida por el Cid, en haberes monedados, tierras, caballos - incluyendo Babieca- y otros bienes, como las espadas Colada y Tizón, y la suma es fastuosa (Duggan, The Cantar de Mio Cid). Amén de los 600 marcos usurpados a Raquel y Vidas antes de iniciar su camino hacia el exilo, el Cid gana 30,000 marcos de oro y plata en la conquista de Valencia; una nueva escaramuza contra el Islam le propina a Ruy Díaz otros 3,000 marcos. La sustanciosa cifra de caballos y otros haberes acumulados por Rodrigo Díaz le permite hacer pingües donaciones a San Pedro de Cardeña y enriquecer a los infantes de Carrión, al rey, a sus vasallos, a su mujer y a sus hijas. El préstamo que Rodrigo pide a Raquel y Vidas y los bienes que el héroe épico quiere dejar en prenda es una actividad económica regulada con todo detalle en el Fuero viejo de Castilla (GriceHutchison, Early Economic Thought in Spain 1177-1740, 3). El Cid, dice el Poema, no gasta la fortuna adquirida en sí mismo, sino que con él medran también el rey y los suyos.

Veamos a continuación un listado representativo de las expresiones lingüísticas que tienen connotación crematística en el Poema de Mio Cid y que no se refieren literalmente a una 
situación mesurable en términos monetarios. Las expresiones crematísticas que han caído en desuso o que han cambiado de significado van marcadas con un guión corto y son el mejor indicador de cómo los cambios de mentalidad acompañan a los cambios lingüísticos en el área del valor y la economía:

-Preciar, por dar precio (apreciar) o valorar: "Non lo preçio un figo" (v. 77); "Déxanla a Mio Çid, todo esto non preçian nada" (v. 475).

-Caros, por estimados o queridos: "Amigos caros" (v. 103).

-Barata, por refriega: "En el passar de Xúcar í veriedes barata" (v. 1228).

-Pagado, por agradecido: “ide qué será pagado?” (v. 129); "Yo d'esso me pago" (v. 141); "E só vuestro pagado" (v. 248); "Mucho era pagado del sueño que á soñado" (v. 410); "mucho era pagado" (v. 412); “¡Dios que bien pagó!” (v. 806); “Todos son pagados" (v. 809); "De aquesto fue pagado" (v. 1296); "los otros bien pueden fincar pagados" (v. 1782); "Todos ge lo gradecen e soso pagados son" (v. 2856). "désto es pagado" (v. 825); "Nós pagados fincamos, señor de la tu part" (v. 854).

También se documenta el sentido actual de pagado, por remunerado: "¿de que será pagado/ o qué ganancia nos dará este año?" (vv. 129-30); "Todos sodes pagados e ninguno por pagar" (v. 536); "Qué bien pagó a sus vasallos mismos" (v. 847); "juntos con sus mesnadas, conpeçolas de pagar" (v. 1083).

-Ser menguado y mezquino, por ser pobre: "Mientras que vivades, non seredes menguados" (v. 158); "En todos los sos non fallariedes un mesquino" (v. 849).

-Oro y dinero seguidos de adjetivos calificativos para denotar "bueno", "falso" o "riqueza", frente al término neutro "averes monedados" (v. 172): aparece "dinero malo" en el v. 165 frente a "oro esmerado" del v. 113. Otras instancias se encuentran en "Non prendré de vos quanto vale un dinero malo" (v. 503); "Sabet, non vos daré a vós un dinero malo" (v. 1042).

-Contado, por famoso: "Campeador contado" (v. 142 y 493); "Martín Antolínez, un burgalés contado" (v. 193); "Ante Ruy 
Díaz el lidiador contado" (v. 502); "Por ir con él omnes contados" (v. 826); "Ante Ruy Díaz el lidiador contado" (v. 502). Contar también se documenta en el Poema de Mio Cid con el significado actual de contar, por computar: "Non las quiero contar" (v. 1310).

-Despensa, por bienes monetarios y por gasto: "Si essa despensa vos falleçiere o vos menguare algo" (v. 258); "Por un marco que despendades, al monasterio daré yo quatro" (v. 260); es decir, despensa, tiene el significado de depósito o conjunto de vituallas; y también se utiliza con el significado de gasto "por un marco que despendades, al monasterio daré yo quatro" (v. 260); en cambio, "conducho" es el abastecimiento, despensa o provisiones de viaje: "yo les manadaré dar conducho mientra que por mi tierra fueren" (v. 1356).

-Cumplido, por honrado y abastecido: "La mi mugier tan conplida" (v. 278); "barba tan complida" (v. 298).

-Quitar, por abandonar: "Por el regno quitar" (v. 393); "La tierra del rrey Alfonso esta noch la podremos quitar" (v. 423); "Quitar quiero Casteion oid escuelas de Minaya" (v. 529) —escuelas en el sentido de séquito de vasallos-; "Çiento moros e çiento moras quiero las - quitar" (v. 534). "El castiello quiso quitar" (v. 852); "Quando quitó a Alcocer" (v. 855).

-Quitar, por librar, eximir o pagar: "quitedes mil missas" (v. 822); "El rrey lo pagó todo e quito se va Minaya" (v. 1539); "de mí sean quitos e vayan a la gracia del criador" (v. 1370).

También se documenta el significado actual de quitar, por sustraer: "en Sancta María de Burgos quitedes mill missas / lo que rromaneçiere daldo a mi mugier e a mis fijas" (vv. 821-822).

-Catar, por mirar y no con el sentido de calcular: "E él a las niñas tornólas a catar" (v. 371).

-Comedir, por ponderar mentalmente: "Comidiós Mio Çid" (v. 507). Generalmente comedir es usado en la fórmula Pensó e comidió, con el significado de ponderar: "Una grant ora el rey pensó e comidió" (vv. 1889, 1932, 2828 y 2935). Comedir anticipa cierto recelo en todas las circunstancias en las que aparece, ya que se usa dentro de un entorno en el que se pro- 
porciona una mala noticia. "Commo lo comidía el que en buen hora nació" (v. 2020); "non sabemos qué s'comidrán" (v. 3578).

-Prestar, por prestancia, apariencia: "Un cavallero de prestar" (v. 671); "Minaya, caballero de prestar" (v. 1431); "El obispo don Ieronimo, coronado de prestar" (v. 1460).

-Deudo (debdo), por vasallo: "Los que el debdo avedes" (v. 709) — debdo significa "deber vasallaje".

-Falsar, por dañar, no por falsificar: "Mas nol' pueden falsar" (v. 713) - falsar, significa aquí perforar la armadura.

Valer, por ayudar: "val a Mio Cid el campeador" (v. 241); "Dios nos valió" (v. 831); "Dios le iva valiendo" (v. 1096); véase el contraste entre "El Criador vos salve" (v. 1115) y "Vos valga"; "el Criador vos vala con todos los sos santos" (v. 2277).

Valor, por valioso y por valeroso, "onde salíen condes de prez e de valor" (v. 3444).

-Menos valer, por minusvalía legal: "por quanto les fiziestes menos valedes vos" (v. 3268); "por el campeador mucho valiestes mas" (v. 3318). Véase también la acusación de "menos valer" frente a la ponderación de "valer" en: "Creçe compaña por que más valdrá" (v. 296).

-Menguar y minguar, por carecer, faltar o mermar: "Una huesa llena que nada nol'mingua" (v. 821); "La compaña del Cid crece e la del rrey mengó" (v. 2165); "Antes fu minguado, agora rico só" (v. 2494).

El uso de ganar, por conquistar, como en "Por la seña ganar" (v. 712), es muy inferior al de ganar, con el sentido de enriquecer: Entre los vv. 584 y 600 se usan términos referidos a ganar, conseguir y a valor en casi cada verso: "Faremos grant ganancia" (v. 584); "No nos darán dent nada" (v. 585); “¡Ya se nos va la ganançia!" (v. 590); "Al sabor del prender de lo ál non piensan nada" (v. 594); "Nuestra es la ganancia" (v. 598); "Grand aver avemos" (v. 617); "Nada non ganaremos" (v. 620); "Ca el señorío tenemos" (v. 621); "Mio Çid con esta ganancia" (v. 623); "juntos con sus mesnadas, conpeçolas de pagar/ de la ganancia que an fecha, maravillosa e grand: / ; Tan ricos son los sos que non saben qué se an!" (vv. 1083-1086). 
Después de la batalla de Castejón, en la tirada 24, hay también un verbo o un sustantivo casi en cada verso, que tiene que ver con metáfora de valor: "Campeador contado" (v. 493); "Pagar se ía" (v. 495); "Yo vos la suelto e avello quitado" (v. 496). El reiterado uso de las palabras rico, enriquecimiento, y riqueza es asimismo digno de destacar en la tirada 40, donde, como en el caso anterior, se usa verso tras verso: "Daquesta riqueza" (v. 811); "Evades aquí oro e plata" (v. 820); "una huesa llena, que nada nol mengua" (v. 820); "serán dueñas rricas" (v. 825); "A cavalleros e a peones fechos los ha rricos" (v. 848); "Qui a buen señor sirve siempre bive en deliçio" (v. 850); "Nos'pueden den quitar" (v. 984); "Ya cavalleros, apart fazed la ganancia" (v. 985); "Tan rricos que son los sos que non saben qué se han" (v. 1086) —este es el segundo verso del cantar II—; "Agora avemos rriquiza, más avremos adelant" (v. 1269); "Riqueza es que nos acreçe maravillosa e grand" (v. 1648).

Finalmente, el uso de ser abondado, con el sentido de estar bien abastecido - "Los que exieron de la tierra de rritad son abondados" (v. 1245) - inclina la balanza hacia lo cuantitativo y lo mesurable de la bien ponderada riqueza cidiana.

En esta sucinta recopilación, el uso del lenguaje refleja una economía de transición en la que hay resquicios de trueque y apreciatura. El muestreo ejemplifica cómo el lenguaje da forma concreta a lo abstracto en términos cuantitativos. Hemos visto aquí un elevado porcentaje de expresiones relacionadas con la crematística que han caído en desuso o que han cambiado de significado, y estos cambios se han producido en el paso de un sistema en el que dichas expresiones no tenían connotaciones económicas (sino que quizá se usaron por analogía con el pujante crecimiento económico) hacia otro en el que lo económico es el sema dominante.

En conclusión, el concepto de valor en la economía, la patrística, la filosofía, la filología, la cultura y la lingüística ha sido tema de estudio en la cultura occidental desde la Antigüedad y es sujeto de regulación en textos bíblicos, jurídicos y literarios; 
el significado del mismo ha fluctuado y con él también lo han hecho las variantes lexicográficas. Bocados de oro demuestra que "lenguaje" es intercambiable con "valor" en sentido axiológico, y en el Poema de Mio Cid la medra económica y social de Rodrigo Díaz explica en parte la sustanciosa presencia en esta obra de expresiones de valor relacionadas con la crematística y la moral. A la luz de los datos aportados en los preliminares, podemos concluir también que el ajuste monetario y el notorio y súbito enriquecimiento económico de Castilla durante la época medieval debieron motivar la proliferación de las expresiones de valor en el léxico castellano, y que estas no necesariamente aluden a la economía.

\section{REFERENCIAS}

Anales del Instituto de Lingüística, vol. 1-21, Mendoza, Universidad Nacional de Cuyo, 1942.

Argüello, Vicente, Memoria sobre El valor de las monedas de D. Alfonso el Sabio. Mencionadas en las leyes del Espéculo, Fuero real y Partidas, leída a la Real Academia de la Historia, Madrid, Reimpresión de las Memorias de la Real Academia de la Historia, v. 7, [s. a.].

Binswanger, Christopher, Money and Magic. A Critique of Modern Economy in the Light of Goethe's Faust, Chicago, up, 1994.

Bloch, Marc, Esquisse d'une Histoire Monétaire de l'Europe, Paris, Librairie Armand Colin, 1954.

Bocados de oro, Kritische Ausgabe des altspanischen textes, Mechthild Crombach (ed.), Bonn, Romanisches Seminar der Universität Bonn, 1971.

Carreras Artau, Tomás, "De los moralistas españoles. A propósito de la filosofía de los valores y la caracteriología", Las Ciencias, 4, 1939, 119-139.

Coulmas, Florian, Language and Economy, Oxford, Blackwell, 1992. CROMBACH, Mechthild (ed.), véase Bocados de oro. 
Duggan, Joseph J., The Cantar de Mio Cid: Poetic Creation in its Economi and Social Contexts, Cambridge, Cambridge University Press, 1989.

Fitz, Brewster E., "The Prologue to the Lais de Marie de France and the Parable of the Talents: Gloss and Monetary Metaphor", Modern Language Notes, 90, 4, May 1975, 558-564.

Forster, Ricardo, El exilio de la palabra: En torno a lo judio, Buenos Aires, Eudeba, 1999.

Fraser, Lindley M., Economic Thought and Language: A Critique of Some Fundamental Economic Concepts, London, A. \& C. Black, 1937.

García Delgado, José Luis et al., Economía del español, Madrid, Ariel-Fundación Telefónica, 2007.

Garrán Martínez, José María, "La concepción del préstamo y la usura en los maestros salmantinos Francisco de Vitoria y Domingo de Soto", 123-132<http://dialnet.unirioja.es/servlet/articulo? codigo $=785579>$.

Gómez, Adriana, El dinero y las palabras, Buenos Aires, Prometeo Libros, 2005.

Gómez Redondo, Fernando, "Terminología genérica en la Estoria de España alfonsí”, Revista de Literatura Medieval, 1, 1989, 5375.

Gómez Redondo, Fernando, Historia de la prosa medieval castellana, vol. 1 [1998], Madrid, Cátedra, 1998-2007, 4 vols.

Grice-Hutchison, Marjorie, Early Economic Thought in Spain 11771740, Boston, George Allen \& Unwin, 1978.

Grin, François (ed.), Economic Approaches to Language Planning, vol. 121, International Journal of the Sociology of Language, New York, Mouton de Gruyter, 1996.

Helm, Anna H., The Intersection of Material and Poetic Economy. Gustav Freytag's Soll und Haben and Adalbert Stifter's Der Nachsommer, Oxford, Peter Lang, 2009.

Hobbes, Thomas, Leviathan, Parts I and II, Herbert W. Schneider (ed.), New York, The Bobs-Merrill Company, Inc., 1958.

Huerta de Soto, Jesús, The Austrian School Market Order and Entrepeneurial Creativity, Cheltenham, Edward Elgar Publishing Ltd., 2008. 
Lapesa Melgar, Rafael, Crisis históricas y crisis de la lengua española: Discurso leído el día 14 de abril de 1996, Madrid, Real Academia de la Historia, 1996.

Moss, Laurence S. y Christopher K. RYAN (eds.), Economic Thought in Spain. Selected Essays of Marjorie Grice-Hutchison, Aldershot, Cheltenham, Edward Elgar Publishing Ltd., 1993.

Poema de Mio Cid, Ian Michael (ed.), Madrid, Castalia, 1973.

Ponziano Lavatori, Gerard, Language and Money in Rabelais, New York, Peter Lang, 1996.

Real Academia Española, Diccionario de Autoridades, ed. facsímil, Madrid, Gredos, 1963, 3 vols.

Rossi-Land, Ferruccio, Studi in Onore di Emilio Betti, vol. I: Metodologia, Ermeneutica, Problemi Generali, Milan, Giuffre, 1962.

Saussure, Ferdinand de, Curso de lingüística general, Buenos Aires, Losada, 1945.

SCHUCHARD, Barbara, Valor Zu seiner Wortgeschichte im Latenischen und Romanischen des Mittelalters, Bonn, Romanisches Semina der Universität Bonn, 1970.

Schutz, Alexander H., "The Provençal Expression Pretz e Valor", Speculum, 19, 1944, 488-493.

SHELl, Marc, The Economy of Literature, [s. 1.], 1978.

Shell, Marc, Money, Language and Thought, L. A. California, University of California Press, 1982.

The Intersection of Material and Poetic Economy. Gustav Freytag's Soll und haben and Adalbert Stfter's Der Nachsommer, Oxford, Peter Lang, 2009.

VILAR, Pierre, A History of Gold and Money 1450-1920, London, NLB, Atlantic Highlands, Humanities Press, 1976.

Wenzel, Regina Angela, Changing Notions of Money and Language in German Literature from 1509 to 1956, Queenston, Ontario, The Edwiyn Mellen Press, 2003.

ZaragüEtA, Juan, El lenguaje y la filosofía, Madrid, Consejo Superior de Investigaciones Científicas, 1945. 